CLINICAL STUDY

\title{
Preoperative lanreotide treatment in acromegalic patients with macroadenomas increases short-term postoperative cure rates: a prospective, randomised trial
}

\author{
Zhi-gang Mao, Yong-hong Zhu ${ }^{1}$, Hai-liang Tang ${ }^{2}$, Dao-yuan Wang, Jing Zhou ${ }^{1}$, \\ Dong-sheng He, Hai Lan, Bai-ning Luo ${ }^{3}$ and Hai-jun Wang \\ Department of Neurosurgery, The First Affiliated Hospital of Sun Yat-sen University, No. 58, Zhongshan Er Road, Guangzhou 510080, People's Republic \\ of China, ${ }^{1}$ Department of Histology and Embryology, Zhongshan School of Medicine, Sun Yat-sen University, Guangzhou 510080, People's Republic of \\ China, ${ }^{2}$ Department of Neurosurgery, Hua-shan Hospital affiliated to Fudan University, Shanghai 200040, People's Republic of China and ${ }^{3}$ Department of \\ Radiology, The First Affiliated Hospital of Sun Yat-sen University, Guangzhou 510080, People's Republic of China
}

(Correspondence should be addressed to H-j Wang; Email: drhaijun.wang@gmail.com)

\begin{abstract}
Objective: To investigate whether 4-month preoperative lanreotide treatment would improve the surgical cure rate of newly diagnosed acromegalic patients with macroadenomas.

Design: A prospective, randomised study.

Methods: After a baseline evaluation, patients were randomly assigned to 4-month preoperative treatment with lanreotide (starting with $30 \mathrm{mg} / 2$ weeks i.m. and increasing to $30 \mathrm{mg} /$ week i.m. at week 8 if mean $\mathrm{GH}>2.5 \mu \mathrm{g} / \mathrm{l}$ on $\mathrm{GH}$ day curves; pretreatment group, Group 1) or to transsphenoidal surgery (direct surgery group, Group 2). Cure was evaluated 4 months postoperatively primarily by fasting IGF1 less than or equal to age-adjusted upper limit of normal.

Results: A pool of 108 patients was randomly divided into two groups. Five patients in each group were lost to follow-up during the study period, so 49 patients in each group were analysed. At baseline, no difference was observed between the two groups. Cure was established in 24 of $49(49.0 \%$, 95\% confidence interval (CI), 35.0-63.0\%) pretreated patients (Group 1) versus 9 of $49(18.4 \%, 95 \%$ CI, 7.6-29.2\%) direct surgery patients (Group 2; $P=0.001$ ). Surgical morbidity was recorded in 12 patients $(12.2 \%)$ and was similar in Group 1 and 2 patients ( 14.3 and $10.2 \%$ respectively; $P=0.538$ ). The postoperative hospital stay was similar between groups: being $4.5 \pm 1.6$ days in Group 1 vs 4.8 \pm 1.9 days in Group $2(P=0.328)$.

Conclusions: Pretreatment with lanreotide before transsphenoidal surgery improves surgical cure rates in patients with GH-secreting pituitary macroadenomas. Pretreatment does not affect surgical complications or duration of hospital stay (ClinicalTrials.gov number, NCT00993356).
\end{abstract}

European Journal of Endocrinology 162 661-666

\section{Introduction}

Acromegaly is a rare disease caused by a GH-secreting adenoma or (rarely, about 1\%) by excessive GH-releasing hormone secretion, usually by a carcinoid tumour of the lung or gastrointestinal tract (1). The incidence of acromegaly is about 3-4 per million per year and the prevalence is 60-70 per million, and there are no geographical or sex differences (2). Clinical features of acromegaly include acral enlargement, prognathism, jaw malocclusion, arthropathy, carpal tunnel syndrome, hyperhydrosis, sleep apnoea and visceromegaly $(3,4)$.

Transsphenoidal neurosurgery, which allows selective removal of pituitary adenomas, is the current first treatment for acromegaly in the majority of patients. Its effects on GH and insulin-like growth factor 1 (IGF1) secretion are rapid, and the operations have low morbidity and very low mortality $(5,6)$. However, surgery for macroadenomas causing acromegaly has a much lower success rate than that for microadenomas. In experienced hands, microadenomas can be cured around $90 \%$ of the time, whereas with macroadenomas the figure is around $50 \%$ (7). This is particularly true with tumours that extend into the cavernous sinus, where surgical success is $<50 \%$ (8). Medical treatment of acromegaly with somatostatin analogues (SSAs) can lead to normalised GH and IGF1 levels in up to $60 \%$ of cases (9) and relief of symptoms (3). Lanreotide is a synthetic SSA, a naturally occurring inhibitory hormone which blocks the release of several other hormones, including $\mathrm{GH}$, thyrotrophin, insulin and glucagon. SSA treatment may cause shrinkage of GH-secreting pituitary adenomas $(9,10)$. Theoretically, this could improve the likelihood of a radical resection, 
particularly in macroadenomas. Furthermore, it has been suggested that SSA treatment softens the tumour parenchyma and thereby facilitates tumour removal (11). Finally, it has been reported that SSA pretreatment leads to a shortening of postoperative hospital stay (12).

Previous studies addressing preoperative SSA treatment and subsequent surgical cure rates are conflicting, reporting a benefit $(12,13)$ or no difference with SSA treatment $(11,14,15)$. Since most reported studies were rather small and were made in retrospect, we conducted a prospective, randomised study to investigate whether 4-month preoperative lanreotide treatment would improve the surgical cure rate of newly diagnosed acromegalic patients with macroadenomas. We also aimed to investigate whether there were differences in the incidence of surgical complications and duration of neurosurgical hospital stay.

\section{Patients and methods}

\section{Patient selection}

From January 1, 2004 to December 30, 2007, patients with newly diagnosed active acromegaly due to GH-secreting macroadenomas were considered eligible for the study. A pituitary macroadenoma was more than $10 \mathrm{~mm}$ in size. The inclusion criteria were as follows: newly diagnosed, previously untreated patients with a GH nadir more than $2.5 \mu \mathrm{g} / \mathrm{l}$ during a standard $75-\mathrm{g}$, 2-h oral glucose tolerance test (OGTT); IGF1 levels at least 1.3 times the upper limit of the age-adjusted normal range (ULN); pituitary macroadenomas verified by a pituitary magnetic resonance imaging (MRI) scan; and age between 18 and 80 years. The exclusion criteria were as follows: immediate surgery indicated by clinical criteria, pregnancy, contraindications on MRI scan, and patients judged not suitable to participate in the study for other reasons such as personality disorders and alcohol abuse. In this study, the patients weren't selected based on response to a somatostatin test. A power calculation verified that 48 patients in each group would be necessary to detect an increase in cure rate from $15 \%$ (9) to $40 \%$ with an $\alpha$ error level of $5 \%$ and a $\beta$ error level of $80 \%$. Allowing for a follow-up loss rate of $10 \%$, the enrolment was closed when 108 patients were included, and 54 patients were allocated to each group.

The trial was performed in the Department of Neurosurgery, The First Affiliated Hospital of Sun Yatsen University, Guangzhou, People's Republic of China. The study was previously approved by the Institutional Review Board of the First Affiliated Hospital, Sun Yatsen University. Written informed consent was obtained from each patient before randomisation. The study is registered at ClinicalTrials.gov (NCT00993356).

\section{Treatment plan}

After a baseline evaluation, patients were randomised to 4-month preoperative treatment with lanreotide (Somatuline LA, Ipsen, Paris, France; pretreatment group, Group 1) or to transsphenoidal surgery (direct surgery group, Group 2). Group 1 patients received lanreotide for 16 weeks before the surgical resection (starting with $30 \mathrm{mg} / 2$ weeks i.m. and increasing to $30 \mathrm{mg} /$ week i.m. at week 8 if mean $\mathrm{GH}>2.5 \mu \mathrm{g} / \mathrm{l}$ on the $\mathrm{GH}$ day curve (GHDC); GHDC: $9 \times 30$-min samples collected in the morning after an overnight fast via an indwelling catheter inserted in an arm vein and while the patient was resting).

In both groups, surgical resection (transsphenoidal adenomatectomy) was performed by two neurosurgeons dedicated to the treatment of pituitary tumours ( $\mathrm{Z} \mathrm{M}$ and $\mathrm{H} \mathrm{W}$ ). The surgical results were assessed 16 weeks following surgery, and mean $\mathrm{GH}>2.5 \mu \mathrm{g} / \mathrm{l}$ in a GHDC was subsequently started on lanreotide (starting with $30 \mathrm{mg} / 2$ weeks i.m. and increasing to $30 \mathrm{mg} /$ week i.m. at 8 weeks later if mean $\mathrm{GH}>2.5 \mu \mathrm{g} / \mathrm{l}$; Fig. 1).

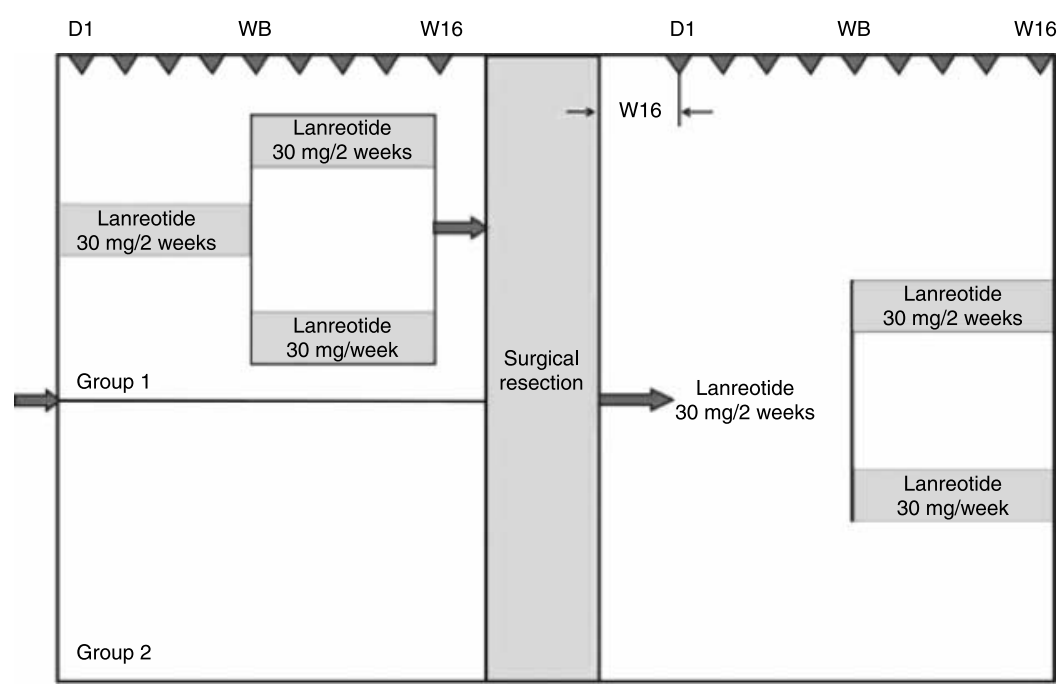

Figure 1 Study protocol. D, day; W, week. 


\section{Imaging assessments}

Tumour size was estimated from MRI studies performed prior to study entry, after lanreotide treatment but prior to surgery (Time 1) and after surgery (Time 2). The MRI scans consisted of T1W spin echo sequences (e.g., TR: 500-600 ms, TE: $15 \mathrm{~ms}$ ) in coronal and sagittal planes constructed as contiguous slices $3 \mathrm{~mm}$ thick or less and performed at $1.5 \mathrm{~T}$. All assessments were performed by a single neuroradiologist, and scans were presented for evaluation without clinical details. Tumour volumes were calculated according to the formula volume $=$ height $\times$ length $\times$ width $\times \pi / 6$ (Ref. (16)). Maximum tumour dimensions were measured in sagittal (vertical height and anterior-posterior length) and coronal (width) views.

\section{Assays}

Serum GH levels were measured by a two-site chemiluminescent immunometric assay (Immulite/ Immulite $1000 \mathrm{GH}$ (hGH) kit, EURO/DPC Ltd, Gwynedd, UK, intra-assay coefficient of variation (CV): 5.3-6.5\%, interassay $\mathrm{CV}$ : $5.7-6.2 \%$, calibration range: up to $40 \mathrm{ng} / \mathrm{ml}(52 \mu \mathrm{g} / \mathrm{l})$, sensitivity: up to $0.01 \mathrm{ng} / \mathrm{ml}$ $(0.013 \mu \mathrm{g} / \mathrm{l}))$. Serum IGF1 levels were measured by a two-site immunoenzymometric assay (OCTEIA IGF1 kit, Immunodiagnostic Systems Ltd, Boldon, UK, expected values depending on age (20-30 years: $11.7-36.1 \mathrm{nmol} / \mathrm{l} ; 30-40$ years: $2.9-25.8 \mathrm{nmol} / \mathrm{l}$; 40-50 years: $6.4-19.3 \mathrm{nmol} / \mathrm{l} ; \quad 50-60$ years: $4.6-27.5 \mathrm{nmol} / \mathrm{l}$; $60-70$ years: $3.9-25.7 \mathrm{nmol} / \mathrm{l} ;>70$ years: $6.6-25.0 \mathrm{nmol} / \mathrm{l}$; intra-assay $\mathrm{CV}$ : $2.3-3.5 \%$; interassay CV: $7.0-7.1 \%$; sensitivity: $0.25 \mathrm{nmol} / \mathrm{l})$ ).

\section{Statistical analysis}

The aim of the study was to investigate whether 4-month treatment with lanreotide before transsphenoidal surgery in newly diagnosed acromegalic patients with macroadenomas would improve the outcome, using cure rate at a 4-month postoperative evaluation as the primary end point. Cure was evaluated 4 months postoperatively primarily by fasting IGF1 less than or equal to age-adjusted ULN. Secondary end points included postoperative hospital stay duration and complication rates. Quantitative data are presented as means \pm S.D., and qualitative data are presented as percentages. Comparisons among groups were performed using Student's $t$-test for quantitative data and the Pearson's $\chi^{2}$ test for qualitative variables. Statistical analysis was performed using the Statistical Program/ SPSS for Windows, version 11.5 (Chicago, IL, USA). A $P$ value (two-tailed) of $<0.05$ was considered statistically significant.

\section{Results}

\section{Baseline patient characteristics}

Of the 128 acromegalic patients with macroadenomas, 112 fulfilled the inclusion criteria and were recruited for the trial; four refused to participate. Two groups of 54 patients each were obtained from a randomisation of 108 patients. Five patients of each group were lost to follow-up during the study period; therefore, 49 patients of each group were analysed in this study. At baseline, no difference was observed between the two groups in gender, patient age, GH nadir during OGTT, IGF1, type of macroadenoma or tumour volume, nor in the rates of hypertension, electrocardiogram abnormalities, left ventricular hypertrophy, ventricular or supraventricular tachycardia, or sleep apnoea (Table 1).

\section{Effect of Ianreotide treatment on surgical outcome}

Cure, as defined by IGF1 less than or equal to the ULN 4 months postoperatively, was established in 24 of 49 (49.0\%, 95\% confidence interval (CI), 35.0-63.0\%) pretreated patients (Group 1) versus 9 of $49(18.4 \%$, 95\% CI, 7.6-29.2\%) direct surgery patients (Group 2; $P=0.001)$. Cure was also estimated using age-adjusted

Table 1 Baseline data according to treatment group.

\begin{tabular}{|c|c|c|c|}
\hline Characteristic & $\begin{array}{c}\text { Group } 1 \\
(n=49), n(\%)\end{array}$ & $\begin{array}{c}\text { Group } 2 \\
(n=49), n(\%)\end{array}$ & $\boldsymbol{P}$ \\
\hline \multicolumn{3}{|l|}{ Gender } & 0.536 \\
\hline Male & $31(63.3)$ & $28(57.1)$ & \\
\hline Female & $18(36.7)$ & $21(42.9)$ & \\
\hline Age (years) $^{a}$ & $48.5 \pm 12.4$ & $43.8 \pm 14.1$ & 0.436 \\
\hline $\mathrm{GH}$ nadir during & $20.4 \pm 15.7$ & $18.9 \pm 16.3$ & 0.247 \\
\hline \multicolumn{4}{|l|}{ OGTT $(\mu \mathrm{g} / \mathrm{l})^{\mathrm{a}}$} \\
\hline Mean (range) & $21.5(3.2-48.5)$ & $19.8(2.9-45.7)$ & \\
\hline IGF1 (nmol/l) $)^{a}$ & $87.9 \pm 25.1$ & $96.1 \pm 23.7$ & 0.083 \\
\hline \multicolumn{3}{|l|}{ Type of macroadenoma } & 0.758 \\
\hline Intrasellar & $15(30.6)$ & $12(24.5)$ & \\
\hline Suprasellar & $25(51.0)$ & $26(53.1)$ & \\
\hline Invasive & $9(18.4)$ & $11(22.4)$ & \\
\hline Tumour volume $\left(\mathrm{cm}^{3}\right)^{a}$ & $14.1 \pm 8.2$ & $12.5 \pm 7.9$ & 0.069 \\
\hline \multicolumn{3}{|l|}{ Hypertension } & 0.678 \\
\hline Yes & $18(36.7)$ & $20(40.8)$ & \\
\hline No & 31 (63.3) & $29(59.2)$ & \\
\hline \multicolumn{3}{|l|}{ ECG abnormalities } & 0.686 \\
\hline Yes & $27(55.1)$ & $25(51.0)$ & \\
\hline No & $22(44.9)$ & $24(49.0)$ & \\
\hline \multicolumn{3}{|c|}{ Left ventricular hypertrophy } & 0.585 \\
\hline Yes & $9(18.4)$ & $7(14.3)$ & \\
\hline No & $40(81.6)$ & $42(85.7)$ & \\
\hline \multicolumn{3}{|c|}{ Ventricular or supraventricular tachycardia } & 0.564 \\
\hline Yes & $8(16.3)$ & $6(12.2)$ & \\
\hline No & $41(83.7)$ & $43(87.8)$ & \\
\hline \multicolumn{3}{|l|}{ Sleep apnoea } & 0.538 \\
\hline Yes & $7(14.3)$ & $5(10.2)$ & \\
\hline No & $42(85.7)$ & $44(89.8)$ & \\
\hline
\end{tabular}

OGTT, oral glucose tolerance test; ECG, electrocardiogram.

avalues given as means \pm s.D. 
cut-off levels of IGF1 ranging from 80 to $120 \%$ of the ULN (Table 2). Pretreatment significantly increased cure rates as evaluated by IGF1 at cut-off levels ranging from 90 to $120 \%$ of the ULN $(P=0.025-<0.001)$. Only 1 of the 11 patients with signs of cavernous sinus invasion in the direct surgery group (Group 2) was cured. However, 4 of 9 patients with signs of cavernous sinus invasion after pretreatment with lanreotide were cured (Group 1). When adding a GH nadir during an OGTT $\leq 1.0 \mu \mathrm{g} / \mathrm{l}$ to the cure criteria, five patients lost their status of being cured. Thus, the overall cure rate was reduced to $38.8 \%$ (Group 1) and $18.4 \%$ (Group 2) respectively $(P=0.025)$.

\section{Effect of Ianreotide treatment on tumour volume}

In the pretreated patients (Group 1), all had reduction of their adenoma size after 4-month lanreotide treatment (median percentage was $34.8 \%$ (range $7.5-62.5$ )). Among those with tumour volume reduction, 42 $(85.7 \%)$ showed shrinkage $>20 \%$ (Fig. 2). Initial tumour volume $\left(13.5 \pm 7.8\right.$ vs $14.6 \pm 8.5 \mathrm{~cm}^{3}$; $P=0.218$ ) was equally distributed among cured and non-cured patients. However, there was a difference in tumour volume change during pretreatment $(-45$ \pm 18 vs $-21 \pm 15 \% ; P=0.003)$ between the cured and non-cured patients.

\section{Complications of surgery}

No operative or perioperative deaths occurred. Surgical morbidity was recorded in 12 patients $(12.2 \%)$ and was similar in Group 1 and 2 patients (14.3 and 10.2\% respectively; $P=0.538$ ). Most complications were mild and caused no permanent disability. The most frequent complication was hyponatraemia (defined as $130 \mathrm{mmol} / \mathrm{l}$ serum sodium concentration), which occurred in four patients (three in Group 1 and one in Group 2), and was responsive to simple water restriction alone in all patients. Difficult intubation requiring postponement of the surgery for one day and a subsequent one-day stay in the intensive care unit were encountered in three patients (one in Group 1 and two in Group 2). Two patients (one in each group) experienced hypoxaemia during anaesthesia without clinical consequences. Two patients (one in each group) experienced transient liquorrhoea, and one patient in Group 2 experienced sinusitis. The postoperative hospital stay was similar between the groups, being $4.5 \pm 1.6$ days in Group 1 versus Group $2(P=0.328)$.

\section{Discussion}

Postoperative remission rates of GH-secreting pituitary adenomas are expected to correlate negatively with the preoperative baseline GH (and probably IGF1) value, the volume of the tumour (especially when exhibiting infiltrative growth) and the consistency of the adenoma. Considering the ability of SSAs to lower GH and IGF1 concentrations, to shrink GH-secreting adenomas, and to possibly soften their consistency, it was thought that SSA pretreatment might improve the results of surgery in acromegaly (15). However, the effect of prior SSA treatment on operative outcome in acromegaly has been controversial. No beneficial effect $(11,14,15,17)$ and improvement of surgical results $(12,13,18-20)$ have both been reported. Inclusion of patients with a microadenoma and of patients who had previously received medical, surgical or irradiation treatment, lack of matching for invasiveness or IGF1 concentration, reliance on single GH values rather than on day

Table 2 Cure rate according to insulin-like growth factor 1 (IGF1) less than or equal to upper limit of normal (ULN) 4 months postoperatively.

\begin{tabular}{|c|c|c|c|c|c|}
\hline $\begin{array}{l}\text { IGF1 as percentage } \\
\text { of ULN }(\%)\end{array}$ & Treatment group & Cured & Not cured & $\boldsymbol{P}$ & Cure rate $(95 \% \mathrm{Cl})$ \\
\hline \multirow[t]{2}{*}{80} & Group 1 & 7 & 42 & 0.538 & $14.3 \%(4.5-24.1 \%)$ \\
\hline & Group 2 & 5 & 44 & & $10.2 \%(1.7-18.7 \%)$ \\
\hline \multirow[t]{2}{*}{85} & Group 1 & 10 & 39 & 0.424 & $20.4 \%(9.1-31.7 \%)$ \\
\hline & Group 2 & 7 & 42 & & $14.3 \%(4.5-24.1 \%)$ \\
\hline \multirow[t]{2}{*}{90} & Group 1 & 19 & 30 & 0.025 & $38.8 \%(25.2-52.4 \%)$ \\
\hline & Group 2 & 9 & 40 & & $18.4 \%(7.6-29.2 \%)$ \\
\hline \multirow[t]{2}{*}{95} & Group 1 & 21 & 28 & 0.009 & $42.9 \%(29.0-56.8 \%)$ \\
\hline & Group 2 & 9 & 40 & & $18.4 \%(7.6-29.2 \%)$ \\
\hline \multirow[t]{2}{*}{100} & Group 1 & 24 & 25 & 0.001 & $49.0 \%(35.0-63.0 \%)$ \\
\hline & Group 2 & 9 & 40 & & $18.4 \%(7.6-29.2 \%)$ \\
\hline \multirow[t]{2}{*}{105} & Group 1 & 26 & 23 & 0.001 & $53.1 \%(39.1-67.1 \%)$ \\
\hline & Group 2 & 10 & 39 & & $20.4 \%(9.1-31.7 \%)$ \\
\hline \multirow[t]{2}{*}{110} & Group 1 & 28 & 21 & $<0.001$ & $57.1 \%(43.2-71.0 \%)$ \\
\hline & Group 2 & 10 & 39 & & $20.4 \%(9.1-31.7 \%)$ \\
\hline \multirow[t]{2}{*}{115} & Group 1 & 29 & 20 & $<0.001$ & $59.2 \%(45.4-73.0 \%)$ \\
\hline & Group 2 & 11 & 38 & & $22.4 \%(10.7-34.1 \%)$ \\
\hline \multirow[t]{2}{*}{120} & Group 1 & 31 & 18 & $<0.001$ & $63.3 \%(49.8-76.8 \%)$ \\
\hline & Group 2 & 11 & 38 & & $22.4 \%(10.7-34.1 \%)$ \\
\hline
\end{tabular}

$\mathrm{Cl}$, confidence interval. 

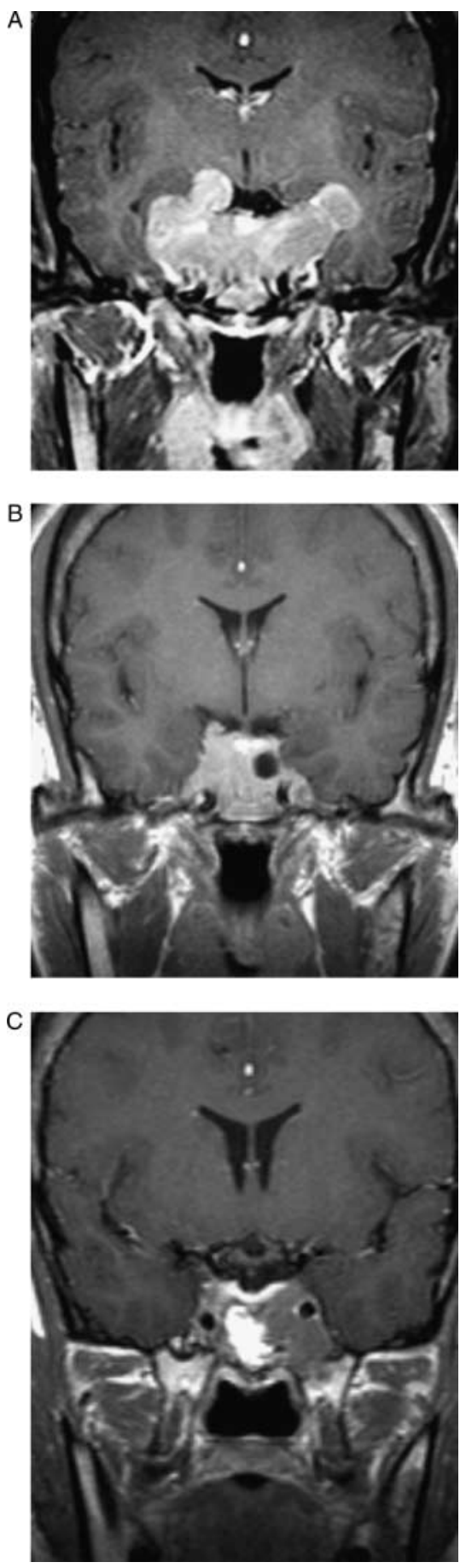

Figure 2 Representative MRI images demonstrating shrinkage of a macroadenoma. The three frames show coronal images at baseline (A) and after 16 weeks of lanreotide therapy (residual volume, $49.4 \%$; B) and 16 weeks after surgical resection (residual volume, $7.6 \%$; C). The patient was cured.

profiles, variable SSA doses and treatment times, as well as liberal criteria for cure $(11-15,17-20)$ are all factors that make it difficult to definitively prove or disprove a positive effect. The current study was designed to avoid these shortcomings. Cure rates are close to $90 \%$ in experienced centres for patients with microadenomas $(21,22)$; such patients were therefore excluded. The lanreotide dose and treatment time were standardised.

This prospective randomised study indicates that preoperative lanreotide treatment of newly diagnosed acromegalic patients before transsphenoidal surgery leads to an increased surgical cure rate in patients with macroadenomas. The cure rates that we observed were $18.4 \%$ in newly diagnosed acromegalic patients with macroadenomas treated directly with transsphenoidal surgery and $49.0 \%$ in patients pretreated for 6 months with lanreotide and remaining on treatment during the surgical procedure $(P=0.001)$. These findings compare favourably with a previous study in which the cure rate was $16 \%$ in direct surgery patients versus $50 \%$ in octreotide-pretreated patients (20). However, in a single-centre study like this, overall cure rates were expected to be higher than the results obtained from a multicentre study like that by Carlsen et al. (20). Secondly, in the present study, cure evaluation was performed at least 16 weeks postoperatively, whereas in the study by Carlsen et al. it was only 12 weeks after the operation (20). Our evaluation time fits the present guidelines, which demand at least a 4-month delay in evaluation when using a long-acting SSA (10). This is thought to prevent a 'hangover' effect of preoperative SSA treatment skewing the postoperative evaluation. Several studies have shown that achieving normal IGF1 levels is a good prognostic factor for acromegaly in terms of morbidity (23-25) and mortality $(26,27)$. There is general agreement that achieving GH levels $\leq 2.5 \mu \mathrm{g} / \mathrm{l}$ is not sufficient for the disease to be considered controlled; it is thought that the persistence of a continuous, albeit minor, hypersecretion of $\mathrm{GH}$ (which can be detected with very sensitive assays) may promote the increased IGF1 levels seen in some patients (28). The situation in which patients have normal IGF1 levels but high GH levels occurs less frequently (29). Thus, in the current study, the criterion that we applied for cure rate was IGF1 less than or equal to age-adjusted ULN.

In contrast with one previous report (12) but in agreement with another (20), pretreatment with SSA did not affect the duration of hospital stay, nor did we observe any difference in surgical complication rates between the study groups. In conclusion, pretreatment with lanreotide before transsphenoidal surgery improves surgical cure rates in patients with GH-secreting pituitary macroadenomas. Pretreatment does not affect surgical complications or duration of hospital stay.

\section{Declaration of interest}

The authors declare that there is no conflict of interest that could be perceived as prejudicing the impartiality of the research reported. 


\section{Funding}

This study was supported by Doctoral Funds of Ministry of Education of People's Republic of China (No. 200805580063) and Guangdong Natural Science Funds (No. 5001729).

\section{Acknowledgements}

The authors are grateful to Dr Carlsen and his colleagues as the design and presentation of this study refer to their paper (Journal of Clinical Endocrinology and Metabolism 200893 2984-2990), and Drs Ben M, Peter $\mathrm{G}$ and Janice $\mathrm{Y}$ for help editing this paper.

\section{References}

1 Biermasz NR, Smit JW, Pereira AM, Frölich M, Romijn JA \& Roelfsema F. Acromegaly caused by growth hormone-releasing hormone-producing tumors: long-term observational studies in three patients. Pituitary 200710 237-249.

2 Mestron A, Webb SM, Astorga R, Benito P, Catala M, Gaztambide S, Gomez JM, Halperin I, Lucas-Morante T, Moreno B, Obiols G, de Pablos P, Paramo C, Pico A, Torres E, Varela C, Vazquez JA, Zamora J, Albareda M \& Gilabert M. Epidemiology, clinical characteristics, outcome, morbidity and mortality in acromegaly based on the Spanish Acromegaly Registry (Registro Espanol de Acromegalia, REA). European Journal of Endocrinology 2004151 $439-446$.

3 Colao A, Ferone D, Marzullo P \& Lombardi G. Systemic complications of acromegaly: epidemiology, pathogenesis, and management. Endocrine Reviews 200425 102-152.

4 Melmed S. Medical progress: acromegaly. New England Journal of Medicine $20063552558-2573$.

5 Ahmed S, Elsheikh M, Stratton IM, Page RC, Adams CB \& Wass JA. Outcome of transphenoidal surgery for acromegaly and its relationship to surgical experience. Clinical Endocrinology 1999 50 561-567.

6 Kreutzer J, Vance ML, Lopes MB \& Laws ER Jr. Surgical management of GH-secreting pituitary adenomas: an outcome study using modern remission criteria. Journal of Clinical Endocrinology and Metabolism 200186 4072-4077.

7 Wass JA, Turner HE \& Adams CB. The importance of locating a good pituitary surgeon. Pituitary 19992 51-54.

8 Fahlbusch R \& Buchfelder M. Transsphenoidal surgery of parasellar pituitary adenomas. Acta Neurochirurgica 198892 93-99.

9 Sheppard MC. Primary medical therapy for acromegaly. Clinical Endocrinology $2003 \mathbf{5 8} 387-399$.

10 Melmed S, Sternberg R, Cook D, Klibanski A, Chanson P, Bonert V, Vance ML, Rhew D, Kleinberg D \& Barkan A. A critical analysis of pituitary tumor shrinkage during primary medical therapy in acromegaly. Journal of Clinical Endocrinology and Metabolism 2005 $904405-4410$.

11 Abe T \& Lüdecke DK. Effects of preoperative octreotide treatment on different subtypes of $90 \mathrm{GH}$-secreting pituitary adenomas and outcome in one surgical centre. European Journal of Endocrinology $2001145137-145$

12 Colao A, Ferone D, Cappabianca P, del Basso De Caro ML, Marzullo P, Monticelli A, Alfieri A, Merola B, Calì A, de Divitiis E \& Lombardi G. Effect of octreotide pretreatment on surgical outcome in acromegaly. Journal of Clinical Endocrinology and Metabolism 199782 3308-3314.

13 Barkan AL, Lloyd RV, Chandler WF, Hatfield MK, Gebarski SS, Kelch RP \& Beitins IZ. Preoperative treatment of acromegaly with long-acting somatostatin analog SMS 201-995: shrinkage of invasive pituitary macroadenomas and improved surgical remission rate. Journal of Clinical Endocrinology and Metabolism 198867 1040-1048.
14 Biermasz NR, van Dulken H \& Roelfsema F. Direct postoperative and follow-up results of transsphenoidal surgery in 19 acromegalic patients pretreated with octreotide compared to those in untreated matched controls. Journal of Clinical Endocrinology and Metabolism 199984 3551-3555.

15 Kristof RA, Stoffel-Wagner B, Klingmüller D \& Schramm J. Does octreotide treatment improve the surgical results of macro-adenomas in acromegaly? A randomized study Acta Neurochirurgica 1999141 399-405.

16 Di Chiro G \& Nelson KB. The volume of the sella turcica. American Journal of Roentgenology, Radium Therapy, and Nuclear Medicine 196287 989-1008.

17 Plöckinger U \& Quabbe HJ. Presurgical octreotide treatment in acromegaly: no improvement of final growth hormone $(\mathrm{GH})$ concentration and pituitary function. A long-term case-control study. Acta Neurochirurgica 2005147 485-493.

18 Lucas-Morante T, García-Uría J, Estrada J, Saucedo G, Cabello A, Alcañiz J \& Barceló B. Treatment of invasive growth hormone pituitary adenomas with long-acting somatostatin analog SMS 201-995 before transsphenoidal surgery. Journal of Neurosurgery 199481 10-14

19 Stevenaert A \& Beckers A. Presurgical octreotide: treatment in acromegaly. Metabolism 199645 (Suppl 1) 72-74.

20 Carlsen SM, Lund-Johansen M, Schreiner T, Aanderud S, Johannesen O, Svartberg J, Cooper JG, Hald JK, Fougner SL, Bollerslev J \& Preoperative Octreotide Treatment of Acromegaly Study Group. Preoperative octreotide treatment in newly diagnosed acromegalic patients with macroadenomas increases cure short-term postoperative rates: a prospective, randomized trial. Journal of Clinical Endocrinology and Metabolism 200893 2984-2990.

21 Ikeda H, Jokura H \& Yoshimoto T. Transsphenoidal surgery and adjuvant gamma knife treatment for growth hormone-secreting pituitary adenoma. Journal of Neurosurgery 200195 285-291.

22 Shimon I, Cohen ZR, Ram Z \& Hadani M. Transsphenoidal surgery for acromegaly: endocrinological follow-up of 98 patients Neurosurgery 200148 1239-1245.

23 Jehle S, Reyes CM, Sundeen RE \& Freda PU. Alternate day administration of pegvisomant maintains normal serum insulinlike growth factor-I levels in patients with acromegaly. Journal of Clinical Endocrinology and Metabolism 200590 1588-1593.

24 Mukherjee A, Monson JP, Jonsson PJ, Trainer PJ \& Shalet SM. Seeking the optimal target range for insulin-like growth factor I during the treatment of adult growth hormone disorders. Journal of Clinical Endocrinology and Metabolism $2003 \mathbf{8 8}$ 5865-5870.

25 Puder JJ, Nilavar S, Post KD \& Freda PU. Relationship between disease-related morbidity and biochemical markers of activity in patients with acromegaly. Journal of Clinical Endocrinology and Metabolism 200590 1972-1978.

26 Swearingen B, Barker FG II, Katznelson L, Biller BM, Grinspoon S, Klibanski A, Moayeri N, Black PM \& Zervas NT. Long-term mortality after transsphenoidal surgery and adjunctive therapy for acromegaly. Journal of Clinical Endocrinology and Metabolism 1998 83 3419-3426.

27 Holdaway IM, Rajasoorya C \& Gamble GD. Factors influencing mortality in acromegaly. Journal of Clinical Endocrinology and Metabolism 200489 667-674.

28 Trainer PJ. Editorial: acromegaly - consensus, what consensus? Journal of Clinical Endocrinology and Metabolism $2002 \quad 87$ $3534-3536$

29 Biermasz NR, Pereira AM, Frölich M, Romijin JA, Veldhuis JD \& Roelfsema F. Octreotide represses secretory-burst mass and nonpulsatile secretion but does not restore event frequency or orderly GH secretion in acromegaly. American Journal of Physiology. Endocrinology and Metabolism 2004286 25-30.

Received 22 December 2009

Accepted 30 December 2009 